\title{
Key Factors \& Features Influencing Selection of Open Source Functional Test Automation Tools
}

\author{
Saravanan.K, Senthil Kumar Balakrishnan
}

\begin{abstract}
Software Testing is an integral part of high quality software development process. To enhance quality, IT Companies are spending huge amount of money, labor and time on testing efforts. Test Automation tools help speed up testing effort, improve quality and also reduce cost in the long run. Currently, a combination of Open Source and Commercial Test Automation tools are employed to perform Functional Testing activities. With wide adoption of tools like Selenium, Open Source Functional Test Automation tools are accepted as a viable alternative for Commercial Tools. Professionals involved in the selection and purchase of a new Test Automation Tool or replace an existing tool are reviewing and analyzing various factors and features that drive them to select a particular tool. Research Reports, Tool Adoption Trends in Industry and Comparative review of various Test Automation Tools are some of the sources for them to guide their tool selection decision. As Open Source tools are accepted as viable alternative to Commercial tools and are highly economical, an empirical assessment focusing on the factors and features influencing the selection of these Open Source Functional Test Automation tools is attempted. This research aims in identifying the key factors and features that influence the selection of these tools by surveying IT Companies located in India who have already adopted these tools.
\end{abstract}

Index Terms: Open Source Test Automation Tools, Selenium, Software Test Automation.

\section{INTRODUCTION}

Quality, Performance and Security are the three key aspects focused in developing a software. Unlike yesteryears, Software Quality is not an after-thought activity and has become a vital activity in the development process. With the research contributions of Glenford Myers, Rex Black and other notable testing gurus, Software Testing has been recognized as a critical activity in the development process and a variety of testing tools are employed to plan, design and execute tests. With today's Agile and DevOps Development models, usage of Test automation tools helps in continuous testing, thereby enhancing quality. Companies are adopting a blend of both Commercial and Open Source Test Automation tools and more than one test automation tool is used for managing the testing requirements. Before adopting a new tool or replacing/augmenting an existing tool, Tool Experts and Managers are reviewing various factors and features influencing the tool selection.

Revised Manuscript Received on September 22, 2019

Saravanan K, Research Scholar, School of Management, Hindustan University, Chennai, India.

Senthil Kumar Balakrishnan, Professor, School of Management, Hindustan University, Chennai, India.
Some of the factors influencing the Selection include Easy to Setup \& Learn, Ease of Scripting, User friendliness, Support for Data Driven Testing, Support for Multiple Operating Systems, Browsers, Scripting Languages, etc., Some of the features expected in the Automation tool include Record/Playback, Report Generation, Record Screenshot, Auto generation of Comments, Debugging, Built-in functions, Add-Ins, Auto-documentation, etc.., This research focuses on identifying the key factors and features that drive the selection of Open Source Functional Test Automation tools by Surveying IT Companies which have already adopted these tools.

\section{REVIEW OF LITERATURE}

Thomas E. Murphy and Jim Scheibmeir (2018) in the Gartner Magic Quadrant Report for Software Test Automation 2018 state that IT Companies are adopting a combination of Commercial tools and Open Source tools for performing their test automation activities. The authors highlight that Open Source test automation tools like Selenium are in high adoption and companies are using more than one test automation tool for their testing efforts. Features and functions of the application, time to productivity \& total cost of ownership are highlighted as the top reasons for selecting a tool.

Joachim Herschmann and Thomas E. Murphy (2017) analyzed the adoption trends of Functional test automation tools in IT Companies and stated that companies adopting 'DevOps' and 'Agile' software development practices are looking for Test Automation tools that can create and maintain effective tests with minimal effort. The authors also mention that adoption of Open Source Test Automation tools is showing an increasing trend. Selenium, Appium, Cucumber are identified as some of the popular Open Source Functional Test Automation tools in adoption. The authors also predict that machine learning and predictive analytics have a major impact on Test Automation tools. The author also state "Future Test Automation tools are expected to be designed around Robotic Process Automation (RPA)".

Dimensional Research (2017) investigated the Testing Trends in 2017 by conducting a survey of 732 Software Professionals working on Web and Mobile Applications. The report states that $87 \%$ of respondents said that some form of Test Automation is employed but the type of tools vary. 
$12 \%$ reported that they are still investing only in Proprietary test automation tools like QTP/UFT. Open Source tools are common in organizations adopting Continuous Integration $(62 \%)$ and Selenium, Appium are popular tools in this space.

Diego Lo Giudice (2016) analyzed Testing tools adoption trends and stated that open source testing tools are in high adoption as most of the companies have started adopting Agile and DevOps software development methodologies. Selenium, Appium, Cucumber/Gherkin are specifically mentioned as popular Open Source testing tools in adoption. The author also mentioned the current trend is 'Test Optimization' in which there should be maximum test coverage with minimum test cases and tool vendors like CA are working in this direction.

\section{RESEARCH METHODOLOGY}

\section{A. Research Objectives}

1. To identify the proportion of Manual Testing versus Automated Testing

2. To identify the key factors influencing the adoption of Open Source Software Functional Test Automation Tools. 3. To identify the key features influencing the selection of Open Source Software Functional Test Automation Tools

\section{B. Research Hypothesis}

Null hypothesis Ho: There is no significant relationship between Selection of Open Source Functional Test Automation Tools and factors/features available with the tools.

Alternate hypothesis H1: There is significant relationship between Selection of Open Source Functional Test Automation Tools and factors/features available with the tools.

\section{Data Collection}

In this study we have used Questionnaire method for collecting data from Software Test Automation Professionals working in Indian IT Companies

\section{Sampling Size: 50}

\section{E. Statistical Tools}

Multiple Regression and Garett's ranking technique are used to identify the influencing factors for selection of Open Source Test Automation Tools.

\section{ANALYSIS}

\section{A. Manual Testing Versus Automated Testing}

Manual Testing Versus Automated Testing

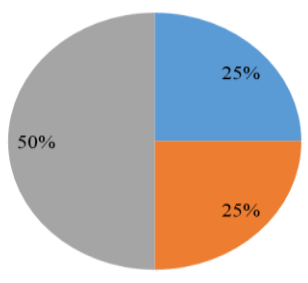

= Automation Tésting

m Manual Testing

m Manual Testing. Automation Testing

Fig 1: Manual Testing Vs. Automated Testing
The above Chart represents the mode of Functional testing performed in Indian IT companies. It is inferred that $25 \%$ of companies perform only Manual Testing and another $25 \%$ of companies perform Testing only using Automation Tools. The remaining 50\% of Companies perform testing adopting both Manual Testing and Automated Testing.

Among the Automated testing tools adopted, the Proportion of Proprietary versus Open Source Automated Testing tools adopted is 50:50. Selenium is the most popular Open Source Functional Test Automation tool adopted followed by Katalon Studio.

\section{B. Factors Influencing the Selection of Open Source Functional Test Automation Tools}

H0: There is no significant relationship between the Selection of Open source functional test Automation Tools and factors influencing the adoption of these tools.

\section{Model Summary}

\begin{tabular}{|l|l|l|l|l|}
\hline & \multicolumn{1}{|c|}{ Model } & \multicolumn{1}{|c|}{$\mathbf{R}$} & $\begin{array}{c}\text { Adjusted } \\
\text { R } \\
\text { Square }\end{array}$ & $\begin{array}{l}\text { Square } \\
\text { Std. Error of } \\
\text { the Estimate }\end{array}$ \\
\hline 1 & $\begin{array}{l}.923(\mathrm{a} \\
)\end{array}$ & .968 & .274 & .93785 \\
\hline
\end{tabular}

Predictors: (Constant), INTEGR, MULBRO, AUTODOCU, CODINGEX, ONLINESU, DTADRI, AVAILABI, MAINTENA, SUPMS, DATABASE, SCRIP, EASESET, EASE, MULTLAN, HANDLI

$\mathrm{R}$ is the correlation, its value is 0.923 and $\mathrm{R}$ square is degree of determination, its value is 0.968. The degree of determination shows the extent to which Integration with other tool, Supports Multiple Browsers, Auto documentation, Data Driven Testing influences the Open Source Automation Testing Tools.

\begin{tabular}{|l|l|l|l|l|l|}
\hline Model & $\begin{array}{l}\text { Sum of } \\
\text { Squares }\end{array}$ & Df & $\begin{array}{l}\text { Mean } \\
\text { Square }\end{array}$ & F & Sig. \\
\hline Regression & 22.582 & 15 & .978 & $\begin{array}{l}3 . \\
488\end{array}$ & $\begin{array}{l}.002 \\
\text { (a) }\end{array}$ \\
\hline Residual & 4.852 & 7 & .443 & & \\
\hline Total & 27.434 & 22 & & & \\
\hline
\end{tabular}

a Predictors: (Constant), INTEGR, MULBRO, AUTODOCU, CODINGEX, ONLINESU, DTADRI, AVAILABI, MAINTENA, SUPMS, DATABASE, SCRIP, EASESET, EASE, MULTLAN, HANDLI

b Dependent Variable: OSTAT

ANOVA table shows that the significant value is less than 0.5 , which means dependent variable I.e., Adoption of Open Source Functional Test Automation Tools is significantly predicted by independent variables namely Supports Multiple Systems, Supports Multiple Browser, Multiple Language, Data Driven, Database Support, Ease of Setup, Availability of Tutorial, Easy to Learn, Coding 
Expertise, Ease of Scripting, Exception Handling, Auto Document, Online support, Maintenance of Scripts, Integration with other Tool at $95 \%$ of confidence level.

\section{Coefficients}

The below table exhibits the influencing factors of selected variables with respect to the Adoption of Open Source Functional Test Automation Tools. Based on the independent variables as represented by regression coefficients and the standardized coefficients values, the change in dependent variable with respect to unit change in respective independent variable can be measured. The B Value of regression coefficient indicated that, which variable was highly Influencing for Open Source Testing Automation Tools.

Among the factors, Coding expertise, Ease of setup and Availability of Tutorials are the main factors influencing the selection of Open Source Testing Automation Tools.

\begin{tabular}{|c|c|c|c|c|c|}
\hline & \multicolumn{2}{|c|}{$\begin{array}{l}\text { Unstd. } \\
\text { Coefficients }\end{array}$} & \multirow[t]{2}{*}{$\begin{array}{l}\text { Std. } \\
\text { Coeff. }\end{array}$} & \multirow[t]{2}{*}{$\mathbf{T}$} & \multirow[t]{2}{*}{ Sig. } \\
\hline & B & $\begin{array}{l}\text { Std. } \\
\text { Error }\end{array}$ & & & \\
\hline Constant & 3.856 & .652 & & 2.478 & $\begin{array}{l}.04 \\
2\end{array}$ \\
\hline $\begin{array}{l}\text { Supports } \\
\text { Multiple } \\
\text { Systems }\end{array}$ & .084 & .018 & .291 & 4.771 & $\begin{array}{l}.00 \\
0\end{array}$ \\
\hline $\begin{array}{l}\text { Supports } \\
\text { Multiple } \\
\text { Browser }\end{array}$ & .277 & .096 & .309 & 2.885 & $\begin{array}{l}.00 \\
4\end{array}$ \\
\hline $\begin{array}{l}\text { Multiple } \\
\text { Language }\end{array}$ & .054 & .026 & .125 & 2.061 & $\begin{array}{l}.04 \\
0\end{array}$ \\
\hline Data Driven & .153 & .067 & .115 & 2.268 & $\begin{array}{l}.02 \\
4\end{array}$ \\
\hline $\begin{array}{l}\text { Database } \\
\text { Support }\end{array}$ & -.005 & .019 & -.246 & $\begin{array}{l}-2.96 \\
1\end{array}$ & $\begin{array}{l}.00 \\
3\end{array}$ \\
\hline Ease Set & .277 & .096 & .306 & 2.885 & $\begin{array}{l}.00 \\
4\end{array}$ \\
\hline $\begin{array}{l}\text { Availability } \\
\text { of Tutorial }\end{array}$ & .368 & .094 & .590 & 3.933 & $\begin{array}{l}.00 \\
0\end{array}$ \\
\hline $\begin{array}{l}\text { Easy to } \\
\text { Learn }\end{array}$ & .084 & .018 & .291 & 4.771 & $\begin{array}{l}.00 \\
0\end{array}$ \\
\hline $\begin{array}{l}\text { Coding } \\
\text { Expertise }\end{array}$ & .097 & .190 & .381 & 3.778 & $\begin{array}{l}.05 \\
0 \\
\end{array}$ \\
\hline $\begin{array}{l}\text { Ease of } \\
\text { Scripting }\end{array}$ & .623 & .094 & .590 & .520 & $\begin{array}{l}.04 \\
2\end{array}$ \\
\hline $\begin{array}{l}\text { Exception } \\
\text { Handling }\end{array}$ & $\begin{array}{l}-0.85 \\
2\end{array}$ & $\begin{array}{l}1.33 \\
5\end{array}$ & .630 & .752 & $\begin{array}{l}.04 \\
7\end{array}$ \\
\hline $\begin{array}{l}\text { Auto } \\
\text { Document }\end{array}$ & .785 & .185 & .408 & 3.874 & $\begin{array}{l}.04 \\
4\end{array}$ \\
\hline $\begin{array}{l}\text { Online } \\
\text { support }\end{array}$ & .496 & .196 & .685 & 4.958 & $\begin{array}{l}.03 \\
2\end{array}$ \\
\hline $\begin{array}{l}\text { Maintenanc } \\
\text { e of Scripts }\end{array}$ & .072 & .188 & .380 & 5.777 & $\begin{array}{l}.00 \\
4 \\
\end{array}$ \\
\hline $\begin{array}{l}\text { Integration } \\
\text { with other } \\
\text { Tool }\end{array}$ & .488 & .954 & .390 & 3.852 & $\begin{array}{l}.00 \\
5\end{array}$ \\
\hline
\end{tabular}

a Dependent Variable: OSTAT
$\mathrm{Y}($ OSTAT $)=3.856+(0.084 *$ Supports Multiple Systems $)+$ $(0.277 *$ Supports Multiple Browser s $)+(0.054 *$ Multiple Language $)+(.153 *$ Data Driven $)-(0.005 *$ Database Support $)+(.277 *$ Ease Set $)+(.368 *$ Availability of Tutorial $)+(0.084 *$ Easy to Learn $)+(.097 *$ Coding Expertise $)+(.623 *$ Ease of Scripting $)-(0.852+$ Exception Handling $)+(0.785 *$ Auto Document $)+(0.496 *$ Online support $)+(0.072 *$ Maintenance of Scripts $)+(0.488 *$ Integration with other Tool)

\section{Features Influencing the Selection of Open Source Functional Test Automation Tools}

Garrett's ranking technique is used to rank the features influencing selection. As per this method, respondents have been asked to assign the rank for all factors and the outcomes of such ranking have been converted into score value. For each factor, the scores of each individual are added and then total value of scores and mean values of score is calculated. The factors having highest mean value is considered to be the most important factor.

\begin{tabular}{|l|c|}
\hline Features Influencing Selection & Rank \\
\hline Report Generation & 1 \\
\hline Record Screenshot & 2 \\
\hline Built-in functions & 3 \\
\hline Generation of Customized Reports & 4 \\
\hline Graphical View & 5 \\
\hline Excel Options/Integration & 6 \\
\hline Generation of Log Files & 7 \\
\hline Record/Playback & 8 \\
\hline Debugging & 9 \\
\hline Batch Testing & 10 \\
\hline
\end{tabular}

From the above table, it is inferred that the top three features influencing the selection of Open Source Functional Test Automation tools include Report generation, Capability to Record screenshot and Availability of Built in functions.

\section{CONCLUSION}

This research reveals that most of the IT Companies are adopting a combination of Manual Testing and Automated Testing. Selenium is the most preferred Open Source Functional Test Automation tool. The research also reveals the top three factors influencing the Selection of Open Source Functional Test Automation tools as Coding Expertise, Ease of Setup and Availability of Tutorials. The top three features influencing the selection of these tools include Report generation, Capability to Record screenshot and Availability of Built in functions. With Open Source Functional Testing tools in high adoption and are being used as complementary to Proprietary tools, this research gives guidelines to IT companies in identifying the critical factors and features that are to be considered before Open Source Functional Test Automation Tool Selection. 


\section{REFERENCES}

1. Glenford J.Myers, The Art of Software Testing, Second Edition, 2004

2. Rex Black, Critical Testing Processes, 2004

3. Allah Bachayo Brohi, Pinial Khan Butt, Shaobo Zhang, Software quality Assurance: Tools and Techniques, 2019

4. Ramli, Ramona \& Ismail, Roslan \& Ahmad, Abdul, Evaluating and selecting software testing tools: a case study, 2014

5. Harsh Bajaj, Choosing the right automation tool and framework is critical to project Success, 2018

6. Joachim Herschmann, Thomas E. Murphy, "Magic Quadrant for Software Test Automation", 27 November 2018 - ID G00347980

7. Joachim Herschmann, Thomas E. Murphy, "Magic Quadrant for Software Test Automation", 20 November 2017 ID: G00320337

8. Dimensional research. Testing trends in 2017: A Survey of software Professionals, January 2017

9. Diego Lo Giudice with Christopher Mines and Sara Sjoblom, "The Forrester WaveTM: Modern Application Functional Test Automation Tools, Q4 2016", December 5, 2016

10. Dhanavandan S, Application of garret ranking Technique: Practical approach, International Journal of Library and Information Studies, Vol. 6(3) Jul-Sep, 2016 